\title{
Compositional variability of San Carlos olivine
}

\author{
SARAH HAMILTON \& SARAH LAMBART \\ Department of Geology and Geophysics, University of Utah, \\ Salt Lake City, UT-USA (sarah.lambart@utah.edu)
}

Natural forsterite(Fo)-rich olivines represent the major constituent of the Earth's upper mantle. Collected at the surface in mantle xenoliths, they are commonly used in scientific research. Many electron microprobe labs use the San Carlos standard USNM111312/44 (1), provided by the Smithonian Institution, for calibrations. Non-USNMdistributed crystals of San Carlos olivine are also often used as starting material in experimental studies (e.g., 2, 3). However, the potential inherent chemical variability of starting materials can affect results and their scientific interpretations. Hence, it is important to characterize the full chemical variability of the San Carlos olivine. Fournelle (4) showed that the USNM material shows limited variability (Fo89.6 to Fo90.5), but that non-standard San Carlos olivines can be significantly more variable, with Fo contents ranging from 87 to $92 \%$. Following these results, we report new major and trace element analyses on grains $(0.5 \mathrm{~mm}->5 \mathrm{~mm})$ of non-USNM San Carlos olivine and compare them with analyses on USNM San Carlos standard compositions. We also investigate the presence of potential grain-scale chemical variations by looking at composition profiles on large (> $5 \mathrm{~mm}$ ) grains. Observed major-element variations (Fo88.4 to Fo91.4) are consistent with Fournelle's results (4). Additionally, we show that minor and trace element concentrations present significant and contrasted variations between grains (e.g., $17 \% \mathrm{Ni}, 28 \% \mathrm{Mn}, 44 \% \mathrm{~V}, 69 \% \mathrm{Al}$, $285 \% \mathrm{P}$, relative). At the scale of the individual grain, however, San Carlos olivines appear relatively homogeneous with no systematic core-rim variations. Results and implications for the use of this material in experimental studies and for interpretations of the petrogenetic processes will be discussed.

(1) Jarosewich et al. (1979), Smithsonian contrib. to the earth sciences 22. (2) Demouchy \& Mackwell (2006), Phys Chem Minerals 33. (3) Wang \& Gaetani (2008), CMP 156. (4) Fournelle (2011), Microsc. Microanal. 17. 